\title{
Behavior Science Emerges
}

\author{
Donald A. Hantula ${ }^{1}$
}

Published online: 8 May 2018

(C) Association for Behavior Analysis International 2018

Welcome to the first volume of Perspectives on Behavior Science (PoBS)! Very observant readers may be confused by the volume number on the cover, but 41 is not a misprint. This is the first branded volume of $P o B S$, but it is the forty first volume of ABAI's flagship journal. The journal's aims and scope have not changed. The name, design, and editorial policies have been adapted to better serve ABAI's scientific mission. As discussed in the last issue (Hantula, Critchfield, \& Rasmussen, 2017), PoBS, like other journals familiar to this audience, has adjusted its policies and practices to meet contemporary challenges in scholarly publishing (Hanley, 2017; Houmanfar, 2016; Houmanfar, 2017, 2018; Madden, 2012, 2013). What remains unchanged is our commitment to publishing review, theory and methodology papers that provide interesting, thought provoking, and challenging perspectives on behavior science.

We seek particularly to build connections between complementary scientific approaches to behavior, explore links between an operant behavior science and other branches of science, and explore implications for policy and application. Several recently published papers (Apel \& Diller, 2017; Barrett, 2016, 2017; Greene, Morgan, \& Foxall, 2017; Houmanfar \& Mattaini, 2016; Moore, 2016; Ortu \& Vaidya, 2017) provide representative examples. It is time to take back our science and to realize Skinner's vision: "We need not retreat in those sectors where science has already advanced. It is necessary only to bring our understanding of human nature up to the same point. Indeed, this may well be our only hope.” (Skinner, 1953, p. 5). Send your best to PoBS!

\section{Editorial Guidelines and Policies}

PoBS will publish conceptual, theoretical, review and methodological papers in behavior science. The general publication practice will be "special-plus" issues in which a

I thank Tom Critchfield, Dave Jarmolowicz, and Erin Rasmussen for their comments.

Donald A. Hantula

hantula@temple.edu

1 Department of Psychology, Temple University, 1701 N 13 St, Weiss Hall, Philadelphia, PA 19122-6085, USA 
special section or special sections with original research papers and commentary, if warranted, will be featured. Additional papers that are not part of these thematic special sections will also appear.

\section{Types of Articles}

These guidelines are a restatement of previous policy changes (Hantula, 2016) as we seek to simplify the submission process for authors and the review process for referees. PoBS submissions will be classified in the following categories:

Original Research Most $P o B S$ articles will fall into this category. Those submissions that pass an initial screening by the editor will be assigned to an associate editor and sent out for full review. $T B A$ had a tradition of publishing expert tutorials that $P o B S$ will continue to uphold. Tutorials will be included in this category, and the title of such papers should begin with the word "Tutorial:" We recognize that the term "research" may mean "empirical study" to many in the behavior science scholarly community; however we also recognize that behavior science and behavior analysis has a long history of theoretical and conceptual research. The difference between the two approaches is merely in the methods. Whether one uses data or concepts, good research and scholarship demands equally rigorous reasoning processes.

Editorial These papers will introduce issues and special section of issues. They will be submitted by invitation only and will be reviewed and edited by the editor or associate editors.

Announcement These will acknowledge guest reviewers and associate editors, advertise special issues, and communicate any news relevant to $P o B S$ readers. They will be submitted by invitation only.

In Memoriam $P o B S$ will continue to pay tribute to influential behavior scientists who have passed on. These papers may be solicited by the editor or submitted and will be reviewed and edited by the editor or associate editors.

Book Review PoBS welcomes reviews of books on behavior science, or books relevant to behavior science. Book reviews will be reviewed and edited by the editor or associate editors and sent out for further review at their discretion.

Commentary These submissions are short articles, and most will be submitted by invitation only. These submissions will be sent out for full review.

Additional Guidelines In keeping with current practices of other journals such as $J E A B$ (Madden, 2012), PoBS will not consider articles that function primarily as reactions to articles published in previous issues.

PoBS will generally not consider publication of papers that appear to be reports of primary source data unless such papers are invited as part of a special section, or appear to be less concerned with data reporting and more concerned for using such data to 
make much broader theoretical or methodological arguments. Two classic examples familiar to many readers are Staddon and Simmelhag's (1971) reexamination of the "superstition" experiment that appeared in Psychological Review, and Herrnstein's (1990) rational choice theory paper that appeared in American Psychologist. An example from our recent pages is Becirevic, Critchfield, and Reed's (2016) article on the acceptability of behavioral terms.

Including offline or supplemental material is encouraged, especially in the case of methodological papers or descriptions of research software.

The terms "behavior analysis" and "behavior science" should be differentiated in $P o B S$ articles. Consistent with contemporary usage, is preferred that that "behavior analysis" is used when referring to the application or practice and "behavior science" is used when referring to the theory or science.

\section{In This Issue}

In a time dominated by daily deadlines, quarterly returns, annual reports, and two-year impact factor windows it is increasingly important to sometimes pause on pursuing the smaller-sooner and reflect on the larger-later. Important ideas and theoretical advances need time to emerge and develop. Quite often their impact is not realized over months or even a few years, but rather decades. Such is the case with the research on the several related topics that enter into the equivalence relation of "emergent behaviors." Sidman's initial empirical studies (Bush, Sidman, \& de Rose, 1989; Sidman, Kirk, \& WillsonMorris, 1985; Sidman \& Tailby, 1982; Sidman, Wynne, Maguire, \& Barnes, 1989) went nearly unnoticed for years, and citations of this work in the two years following its publication (one operational definition of "impact") were few. However Sidman's early experiments laid the groundwork for later research, both basic and applied, as well as theory expansion in Relational Frame Theory (RFT) and research and application development in Acceptance and Commitment Therapy (ACT). These developments were not linear but proceeded in fits and starts, sometimes backtracking to eventually move forward.

A Special Section Emerges Tom Critchfield, Dermot Barnes-Holmes, and Mike Dougher organized and edited a stellar special section on emergent behaviors. Led by a reprint of Sidman's seminal chapter on equivalence relations, these papers summarize research across a multitude of domains and point to a very exciting future. This work is thoroughly behavioral and represents some of the most advanced research, theory, and application in contemporary behavior science. Certainly its treatment of "thought" and "language" does not conform chapter and verse to standard Skinnerian doctrine. But science does not stagnate. The Equivalence Relations, Relational Frames, Acceptance and Commitment literatures have advanced understanding and application far beyond 1957 to grapple with issues from prejudice to psychotherapy and beyond (Arntzen, Granmo, \& Fields, 2017; Avellaneda et al., 2016; Ayres-Pereira, Canovas, Varella, \& de Souza, 2018; Beurms, Traets, De Houwer, \& Beckers, 2017; Bordieri, Kellum, Wilson, \& Whiteman, 2016; Carp \& Petursdottir, 2015; Dixon, Enoch, \& Belisle, 2017; Eilifsen \& Arntzen, 2017; Fox \& Kyonka, 2017; Griffith, Ramos, Hill, \& Miguel, 2018; Guinther, 2017; Jennings \& Miguel, 2017; López-López \& Luciano, 2017; Ma, Miguel, \& Jennings, 2016; Maraccini, Houmanfar, \& Szarko, 2016; May, 
Stewart, Baez, Freegard, \& Dymond, 2017; Mensah \& Arntzen, 2017; Mizael, de Almeida, Silveira, \& de Rose, 2016; Plazas \& Villamil, 2018; Rippy \& Doughty, 2017; Silveira et al., 2016). Regardless of whether this work is labeled as Equivalence Relations, Relational Frames, or Acceptance and Commitment, the similarities outnumber the differences and we hope this special section paves the way for consilience between these diverse and vital research programs.

Additional special sections are in the works, including those focusing on Narrative; Replication and Reproducibility: Concepts, Controversies, Crises and Solutions; Learning: No Brain Required; and Addictions. Current calls for special section papers may be found on the $P o B S$ website. Special sections may be occasioned at the editor's discretion by submission of a particularly interesting article, or may be proposed by readers. Please contact the editor for further information about organizing a special section.

Regularly Scheduled Programming Michael Ghiselin takes a philosophical turn in an expanded version of his invited address at ABAI. This paper furthers the intellectual connections between Darwinian Theory and modern behavior science. Shawn Quigley provides the most comprehensive review of SAFMEDS research available to date. As with most good reviews, Quigley's paper shows us what we know is not necessarily so, and also points the way toward many research avenues. Behavioral fluency has been discussed in these pages previously (Binder, 1996). Matt Tincani and Amanda Guld Fisher review a practitioner focused volume that introduces and explains behavior analysis to speech and language pathologists.

In Memoriam We close the issue with tributes to the lives and careers of two pioneering behavior scientists, Jim Holland and Bernie Weiss. With Jim Holland's wide range of scholarly and other interests, it seemed best to convene a committee to honor his contributions. Tom Critchfield, Doug Greer, Kent Johnson, Joe Morrow, Tony Nevin and Mike Perone penned excellent personal tributes to a pioneer, whose work continues to influence and inspire the field, generating new research and innovative applications. For example, his research on human vigilance (Holland, 1958) inspired additional research 40 years after its publication (Methot \& Huitema, 1998) which led to application in airline baggage screening (Hogan, Bell, \& Olson, 2009). Chris Newland honors Bernie Weiss' groundbreaking career in behavioral toxicology. Dr. Weiss brought behavior into toxicological research, and his inventive contributions continue to advance research (Bushnell, Kavlock, Crofton, Weiss, \& Rice, 2010).

Dedication We dedicate this issue to Murray Sidman whose work inspired generations of behavior scientists.

\section{References}

Apel, A. B., \& Diller, J. W. (2017). Prison as punishment: a behavior-analytic evaluation of incarceration. The Behavior Analyst, 40(1), 243-256. https://doi.org/10.1007/s40614-016-0081-6.

Arntzen, E., Granmo, S., \& Fields, L. (2017). The relation between sorting tests and matching-to-sample tests in the formation of equivalence classes. The Psychological Record, 67(1), 81-96. https://doi.org/10.1007 /s40732-016-0209-9. 
Avellaneda, M., Menéndez, J., Santillán, M., Sánchez, F., Idesis, S., Papagna, V., \& Iorio, A. (2016). Equivalence class formation is influenced by stimulus contingency. The Psychological Record, 66(3), 477-487. https://doi.org/10.1007/s40732-016-0187-y.

Ayres-Pereira, V., Canovas, D. S., Varella, A. A. B., \& de Souza, D. G. (2018). Generalization of equivalence relations from photos to objects by preschool children. Journal of the Experimental Analysis of Behavior. https://doi.org/10.1002/jeab.313.

Barrett, L. (2016). Why brains are not computers, why behaviorism is not satanism, and why dolphins are not aquatic apes. The Behavior Analyst, 39(1), 9-23. https://doi.org/10.1007/s40614-015-0047-0.

Barrett, L. (2017). Reinforcing Rilkean memories. The Behavior Analyst, 40(1), 95-99. https://oi. org/10.1007/s40614-017-0108-7.

Becirevic, A., Critchfield, T. S., \& Reed, D. D. (2016). On the social acceptability of behavior-analytic terms: crowdsourced comparisons of lay and technical language. The Behavior Analyst, 39(2), 305-317. https://doi.org/10.1007/s40614-016-0067-4.

Beurms, S., Traets, F., De Houwer, J., \& Beckers, T. (2017). Symmetry and stimulus class formation in humans: control by temporal location in a successive matching task. Journal of the Experimental Analysis of Behavior, 108(3), 335-350. https://doi.org/10.1002/jeab.282.

Binder, C. (1996). Behavioral fluency: evolution of a new paradigm. The Behavior Analyst, 19(2), 163-197.

Bordieri, M. J., Kellum, K. K., Wilson, K. G., \& Whiteman, K. C. (2016). Basic properties of coherence: testing a core assumption of relational frame theory. The Psychological Record, 66(1), 83-98. https://doi. org/10.1007/s40732-015-0154-z.

Bush, K. M., Sidman, M., \& de Rose, T. (1989). Contextual control of emergent equivalence relations. Journal of the Experimental Analysis of Behavior, 51(1), 29-45. https://doi.org/10.1901/jeab.1989.51-29.

Bushnell, P. J., Kavlock, R. J., Crofton, K. M., Weiss, B., \& Rice, D. C. (2010). Behavioral toxicology in the 21st century: challenges and opportunities for behavioral scientists: Summary of a symposium presented at the annual meeting of the Neurobehavioral Teratology Society, June, 2009. Neurotoxicology and Teratology, 32(3), 313-328. https://doi.org/10.1016/j.ntt.2010.02.002.

Carp, C. L., \& Petursdottir, A. I. (2015). Intraverbal naming and equivalence class formation in children. Journal of the Experimental Analysis of Behavior, 104(3), 223-240. https://doi.org/10.1002/jeab.183.

Dixon, M. R., Enoch, M. R., \& Belisle, J. (2017). Transfers of stimulus function during roulette wagering. Journal of Applied Behavior Analysis, 50(4), 819-824. https://doi.org/10.1002/jaba.417.

Eilifsen, C., \& Arntzen, E. (2017). Effects of immediate tests on the long-term maintenance of stimulus equivalence classes. The Psychological Record, 67(4), 447-461. https://doi.org/10.1007/s40732-0170247-y.

Fox, A. E., \& Kyonka, E. G. E. (2017). Searching for the variables that control human rule-governed 'insensitivity'. Journal of the Experimental Analysis of Behavior, 108(2), 236-254. https://doi. org/10.1002/jeab.270.

Greene, M. N., Morgan, P. H., \& Foxall, G. R. (2017). NEURAL networks and consumer behavior: NEURAL models, logistic regression, and the behavioral perspective model. The Behavior Analyst, 40(2), 393-418. https://doi.org/10.1007/s40614-017-0105-x.

Griffith, K. R., Ramos, A. L., Hill, K. E., \& Miguel, C. F. (2018). Using equivalence-based instruction to teach piano skills to college students. Journal of Applied Behavior Analysis. https://doi.org/10.1002/jaba.438.

Guinther, P. M. (2017). Contextual influence over deriving others' true beliefs using a relational triangulation perspective-taking protocol (RT-PTP-M1). Journal of the Experimental Analysis of Behavior, 108(3), 433-456. https://doi.org/10.1002/jeab.291.

Hanley, G. P. (2017). Editor's note. Journal of Applied Behavior Analysis, 50(1), 3-7. https://doi.org/10.1002 jjaba.366.

Hantula, D., Critchfield, T. S., \& Rasmussen, E. (2017). Swan song. The Behavior Analyst, 40(2), $297-303$. https://doi.org/10.1007/s40614-017-0132-7.

Hantula, D. A. (2016). Expanding the scope: beyond the familiar and beyond the page. The Behavior Analyst, 39(2), 189-196. https://doi.org/10.1007/s40614-016-0078-1.

Herrnstein, R. J. (1990). Rational choice theory: necessary but not sufficient. American Psychologist, 45(3), 356-367. https://doi.org/10.1037/0003-066x.45.3.356.

Hogan, L. C., Bell, M., \& Olson, R. (2009). A preliminary investigation of the reinforcement function of signal detections in simulated baggage screening: further support for the vigilance reinforcement hypothesis. Journal of Organizational Behavior Management, 29(1), 6-18. https://doi.org/10.1080 /01608060802660116.

Holland, J. G. (1958). Human vigilance. Science, 128, 61-67. https://doi.org/10.1126/science.128.3315.61.

Houmanfar, R. (2016). Scholarly discussion and research: a formula for the advancement of science. Journal of Organizational Behavior Management, 36(1), 1-4. https://doi.org/10.1080/01608061.2016.1154412. 
Houmanfar, R. A. (2017). From conceptual analyses to research and practice. Journal of Organizational Behavior Management, 37(1), 1-4. https://doi.org/10.1080/01608061.2017.1274942.

Houmanfar, R. A. (2018). From laboratory to applied settings and beyond. Journal of Organizational Behavior Management, 38(1), 1-4. https://doi.org/10.1080/01608061.2018.1423716.

Houmanfar, R. A., \& Mattaini, M. A. (2016). Leadership and cultural change: implications for behavior analysis. The Behavior Analyst, 39(1), 41-46. https://doi.org/10.1007/s40614-016-0064-7.

Jennings, A. M., \& Miguel, C. F. (2017). Training intraverbal bidirectional naming to establish generalized equivalence class performances. Journal of the Experimental Analysis of Behavior, 108(2), 269-289. https://doi.org/10.1002/jeab.277.

López-López, J. C., \& Luciano, C. (2017). An experimental analysis of defusion interactions based on deictic and hierarchical framings and their impact on cognitive performance. The Psychological Record, 67(4), 485-497. https://doi.org/10.1007/s40732-017-0250-3.

Ma, M. L., Miguel, C. F., \& Jennings, A. M. (2016). Training intraverbal naming to establish equivalence class performances. Journal of the Experimental Analysis of Behavior, 105(3), 409-426. https://doi. org/10.1002/jeab.203.

Madden, G. J. (2012). Lessons from JEAB to JEAB. Journal of the Experimental Analysis of Behavior, 97(1), 1-4. https://doi.org/10.1901/jeab.2012.97-1.

Madden, G. J. (2013). At 100 volumes of JEAB, a brief discussion of change and the road ahead. Journal of the Experimental Analysis of Behavior, 100(1), 1-4. https://doi.org/10.1002/jeab.34.

Maraccini, A. M., Houmanfar, R. A., \& Szarko, A. J. (2016). Motivation and complex verbal phenomena: implications for organizational research and practice. Journal of Organizational Behavior Management, 36(4), 282-300. https://doi.org/10.1080/01608061.2016.1211062.

May, R. J., Stewart, I., Baez, L., Freegard, G., \& Dymond, S. (2017). Arbitrarily applicable spatial relational responding. Journal of the Experimental Analysis of Behavior, 107(2), 234-257. https://doi.org/10.1002 jeab.250.

Mensah, J., \& Arntzen, E. (2017). Effects of meaningful stimuli contained in different numbers of classes on equivalence class formation. The Psychological Record, 67(3), 325-336. https://doi.org/10.1007/s40732016-0215-y.

Methot, L. L., \& Huitema, B. E. (1998). Effects of signal probability on individual differences in vigilance. Human Factors, 40(1), 102-110. https://doi.org/10.1518/001872098779480514.

Mizael, T. M., de Almeida, J. H., Silveira, C. C., \& de Rose, J. C. (2016). Changing racial bias by transfer of functions in equivalence classes. The Psychological Record, 66(3), 451-462. https://doi.org/10.1007 /s40732-016-0185-0.

Moore, D. S. (2016). The developmental systems approach and the analysis of behavior. The Behavior Analyst, 39(2), 243-258. https://doi.org/10.1007/s40614-016-0068-3.

Ortu, D., \& Vaidya, M. (2017). The challenges of integrating behavioral and neural data: bridging and breaking boundaries across levels of analysis. The Behavior Analyst, 40(1), 209-224. https://oi. org/10.1007/s40614-016-0074-5.

Plazas, E. A., \& Villamil, C. W. (2018). Formation of new stimulus equivalence classes by exclusion. Journal of the Experimental Analysis of Behavior. https://doi.org/10.1002/jeab.322.

Rippy, S. M., \& Doughty, A. H. (2017). Adduction of untested derived stimulus relations depends on environmental complexity. Behavioural Processes, 143, 1-3. https://doi.org/10.1016/j. beproc.2017.07.008.

Sidman, M., Kirk, B., \& Willson-Morris, M. (1985). Six-member stimulus classes generated by conditionaldiscrimination procedures. Journal of the Experimental Analysis of Behavior, 43(1), 21-42. https://doi. org/10.1901/jeab.1985.43-21.

Sidman, M., \& Tailby, W. (1982). Conditional discrimination vs. matching to sample: an expansion of the testing paradigm. Journal of the Experimental Analysis of Behavior, 37(1), 5-22. https://doi.org/10.1901 /jeab.1982.37-5.

Sidman, M., Wynne, C. K., Maguire, R. W., \& Barnes, T. (1989). Functional classes and equivalence relations. Journal of the Experimental Analysis of Behavior, 52(3), 261-274. https://doi.org/10.1901/jeab.1989.52-261.

Silveira, M. V., Aggio, N. M., Cortez, M. D., Bortoloti, R., Rico, V. V., \& de Rose, J. C. (2016). Maintenance of equivalence classes and transfer of functions: the role of the nature of stimuli. The Psychological Record, 66(1), 65-74. https://doi.org/10.1007/s40732-015-0152-1.

Skinner, B. F. (1953). Science \& human behavior. New York, NY, US: Free Press.

Staddon, J. E., \& Simmelhag, V. L. (1971). The 'supersitition' experiment: a reexamination of its implications for the principles of adaptive behavior. Psychological Review, 78(1), 3-43. https://doi.org/10.1037 /h0030305. 